\title{
ALGUNS ASPECTES DE L'EVOLUCIÓ DEL DIGITAT DES DEL SEGLE XVI AL XVIII
}

\author{
Maria Lluïsa CORTADA
}

\begin{abstract}
Starting from the theoretical works of Juan Bermudo Declaración de Instrumentos musicales (1555) and Tomás de Santa María Libro llamado Arte de tañer Fantasía (1565), we can appreciate the fingering evolution in the keyboard instruments. The influence of the iberian sources from the sixteenth century spreads to the late eighteenth century theorists $\mathrm{C}$. $\mathrm{Ph}$. $\mathrm{E}$. Bach and Wilhelm Marpurg.
\end{abstract}

Resum

A partir de les obres teòriques de Juan Bermudo Declaración de Instrumentos musicales (1555) i de Tomás de Santa María Libro llamado Arte de tañer Fantasía (1565) podem obersevar l'evolució del digitat en els instruments de teclat. L'influència de les fonts ibèriques del xvı arriba fins els teòrics de finals del s. XVIII C. Ph. E. Bach y Wilhelm Marpurg.

Qui només toca o canta correctament les notes, actua com l'orador que llegeix el seu discurs sense cap expressió;

a l'igual de l'orador que varia el to del seu discurs, el músic ha de trobar la manera d'expressar els sons.

Johann Abraham Peter Schulz ${ }^{1}$

Un aspecte molt important per als instruments de teclat és l'articulació, denominada sovint, equivocadament, fraseig. La funció de l'articulació és la d'unir o separar — com el llenguatge — els sons, cosa ben diferent de la finalitat del fraseig. Un altre element tècnic és la digitació valorada de manera semblant - pels intèrprets actuals - al tempo i la desigualtat rítimica. A la pràctica, cal fer una gran distinció entre els resultats de la digitació antiga i la més moderna, que hom situa a l'entorn del 1800. Les fonts que tenim per tal de reconstruir la digitació antiga per a instruments de teclat són nombroses i presenten un arc ampli que arriba fins a Carl $\mathrm{Ph}$. E. Bach o Friedrich Wilhelm Marpurg.

1. Sulzer, J. G., Allgemeine Theorie der Schönen Künste. Leipzig, 2 v., 1771-1774.

Anuario Musical, 52 (1997) 
El desenvolupament de la digitació segueix de manera fidel, entre el 1500 i el 1700, el canvi del material sonor i la seva formulació musical. Hom treballa sobre un gènere bàsicament diatònic que avança cap al cromatisme, tot alterant progressivament la modalitat envers la conquesta tonal. A manera de resum, podem connectar les seves propietats amb la funció, a través dels segles, de l'ornamentació, el material diatònic o cromàtic, el plantejament modal o tonal, la progressiva estructuració de la frase melòdica, la realització del baix continu i l'aspecte organològic. Aquest procediment pertany a la tècnica implícita de l'instrument, sobretot en allò que es refereix a la part interpretativa quant a la seva força per a suggerir l'articulació i el fraseig.

Una bona part de les històries de la música considera la música ibèrica com una referència que condueix a la reflexió, la qual cosa ens motiva a comparar alguns tractats ibèrics amb altres teòrics del moment. D'una manera generalitzada, s'estableixen tres estils nacionals: l'italià, el francès i l'alemany; aquesta classificació perdura fins al segle xvIII, fet, però, que no fa disminuir l'atenció especial que mereix la cultura musical ibèrica. El renaixement de la música instrumental i vocal que s'originà a la península — fruit de la interrelació de l'escola flamenca i de la situació envers Itàlia-, es va produir, respectivament, als segles XVI i XVII, és a dir, al Segle d'Or. La unitat cultural del moment no ens permet de fer una separació entre la música hispànica i la portuguesa. Tampoc no podem considerar com un fet casual la relació de Domenico Scarlatti amb Portugal i Espanya; més aviat podríem atribuir-la a la influència de la cultura del Mediterrani i a un rerafons polític. No oblidem, però, que Nàpols, Sicília i una part de Milà formaven part de la corona espanyola. Així mateix hem de recordar l'ascendent que al segle XVI tingué la música espanyola sobre la capella papal de Roma, fet que originà «l'Escola romana», formada en bona part per compositors espanyols.

D'entre els teòrics ibèrics excel-leixen dues personalitats: Juan Bermudo (1510-1565) i Tomás de Santa María (1510/1520-1570). Ambdós van desenvolupar els seus coneixements en el clos conventual: el primer era franciscà i el segon dominicà. El llibre de Tomás de Santa María ${ }^{2}$ està confegit d'una manera clara, lògica, ordenada, i mostra per damunt de tot el seu sentit pedagògic. Descriu amb tot detall la diferència entre l'orgue i el clavicordi, tot precisant-ne l'atac — similar a l'orgue i al clavicèmbal-, i distingint el contacte suau produït per les cordes del clavicordi, fet que pot arribar a modificar-ne el so i que fa que Santa María el defineixi com el més subtil dels instruments de teclat. Des del capítol XIII al XIX ofereix una descripció de les tècniques peculiars de l'atac, de la disposició del cos i dels braços, perquè no es mantinguin enrampats, i de la posició de la mà, que recomana de posar rodona tot fent un arc, —com si fos la «d'un gat»—; també comenta el comportament del polze i de la digitació en general. L'autor demostra la seva claredat de criteri i, en certa manera, la seva modernitat respecte a la numeració dels dits de la mà - $1,2,3,4,5-$, que és ben diferent de la que donen els teòrics alemanys Buchner ${ }^{3}$ i Ammerbach ${ }^{4}$, els quals tot partint del número 4 per al dit menovell, segueixen fins a arribar a l'índex i adjudiquen el número 5 al polze:

2. Santa María, T., Libro llamado Arte de tañer Fantasía, assí para Tecla como para Vihuela,... Valladolid 1565. Edició facsímil. [Westmead] (Gran Bretanya): Gregg International Publishers Limited, 1972. 
Capítol XIII, fol. 36v.

De las condiciones que se requieren para tañer con toda perfección y primor:

«Las condiciones (...) son ocho. La primera es tañer a Compas. La segunda poner bien las manos. La tercera herir bien las teclas. La quarta tañer con limpieza y distincion. La quinta correr bien las manos (...) subiendo hazia la parte superior, y baxando hazia la parte inferior. La sesta herir con dedos convenientes. La septima tañer con buen ayre. La octava hacer buenos redobles y quiebros».

Capítol XIV, fol. $37 r$.

Del modo de poner bien las manos:

«Antes que en esta materia entremos, es necessario saber la quenta de los dedos, la qual comiença en el dedo Pulgar, y se acaba en el dedo pequeño, contando successivamente de uno hasta cinco (...) La segunda condicion, que es poner bien las manos, consiste en tres cosas. La primera es, que las manos se pongan engaravatadas como manos de gato, de tal manera que entre la mano y los dedos, en ninguna manera aya Corcoba alguna, mas antes el nascimiento de los dedos ha de estar muy hundido, de tal manera que los dedos esten mas altos que la mano puestos en arco, y asi los dedos quedan mas flechados para herir mayor golpe (...), y entonces suenan las bozes mas rezias y mas enteras, y con mayor espiritu. La segunda cosa, es traer las manos muy cogidas, lo qual se haze allegando los quatro dedos de ambas manos, que son segundo, tercero, quarto y quinto, unos a otros, especialmente pegando el dedo segundo al tercero, lo qual se puede hazer con la mano derecha que con la yzquierda (...) Assi mesmo ha de andar el dedo Pulgar muy caydo, y muy mas baxo que los otros quatro, pero ha de andar doblegado para dentro, de suerte que el medio dedo de la coyuntura adelante, ande debaxo dela palma. (...) Y es impossible poner bien las manos, sin traer encogidos desta manera los sobredichos dos dedos de ambas manos. (...) La tercera cosa es, que de tal manera se pongan las manos, que los tres dedos de cada mano que son segundo, tercero y quarto, anden siempre sobre las teclas (...) Para la buena postura de las manos, y aun para tañer bien, es necessario que los braços de los cobdos a dentro anden llegados al cuerpo, pero sin ninguna fuerça, aunque para subir carreras largas de Corcheas y Semicorcheas con la mano yzquierda, es necessario apartar el cobdo yzquierdo del cuerpo, y assi mesmo para baxar carreras largas de Corcheas y Semicorcheas, con la mano derecha es tambien necessario apartar el cobdo derecho del cuerpo».

Capítol XV, fol. 37v.

Del modo de herir las teclas:

3. BuChNer, J., Fundamentum, sive ratio vera, quae docet quemvis cantum planum... Zurich, Zentralbibliotek, M. 284. Hi exposa que: 1). S'ha de digitar en funció del que segueix. 2). Quatre semicorxeres o fuses descendint de grau: 3,2,1,2. 3). Quatre notes ascendint de grau amb valors iguals: 1,2,1,2.4). Aconsella en molts casos: ascendint, 1,2,3,2, i descendint: 3,2,1,2. 5). Utilitzar els mateixos dits per a la mà esquerra. 6). Aconsella l'ús de l'índex i l'anular en els intervals de 3a. 7). Aconsella l'ús de l'index 0 el 5è dit en els intervals de 5a i 6a (exceptuant si segueix l'8a). 8). Aconsella el polze i el 5è dit per les 8es.

4. Амmerbach, E.N., Orgel oder Instrument Tabulatur. Leipzig, 1571. Les pautes són similars a la Península Ibèrica i a Itàlia: el digitat segueix la brevetat de les articulacions i del fraseig. La idea que la música s'ha d'ornamentar tradueix l'essència de la tècnica de teclat que es va configurant en funció de l'ornament. 
«La tercera condicion, que es herir bien las teclas, consiste en seys cosas. La primera es herir las teclas con las yemas de los dedos, de tal manera que las Uñas no alleguen ni toquen con mucho a las teclas (...) Quando se hiere con las uñas, se cometen dos grandes defectos. El primero es, que suena mucho la madera de las teclas, y poco las bozes y tambien desmayadas y sin espiritu. El segundo defecto es, que se tañe suzio y estropajoso, y por consiguiente dessabrido para los oydos (...) La segunda cosa, es herir las teclas rezio y con impetu (...) La tercera cosa es, que ambas a dos manos hieran las teclas ygualmente, esto es, que la una mano no hiera mas rezio, ni mas quedo que la otra (...) La quarta cosa, es no herir las teclas de alto, para lo qual es necessario traer los dedos cerca de las teclas, y despues que cada dedo aya herido la tecla, levantarle muy poco, y de mas desto han de herir los dedos cayendo derechos, y en el mesmo derecho levantarle, de suerte que buelvan a ponerse en el mesmo lugar y disposicion que antes estavan. (...) La quinta cosa, es hundir las teclas todo lo que buenamente pudieren baxar, de suerte que si el instrumento fuere Monacordio, los toques levanten bien las cuerdas, mas de tal manera que las bozes no salgan de su tono subiendo de boz (...) La sexta cosa es, que despues de herir las teclas, ni se aprieten tanto los dedos sobre ellas (porque demas de salir las bozes de tono subiendo de boz, se entorpecen las manos, como si las atassen) ni tampoco se afloxen los dedos, de manera que las bozes desmayen (...) De suerte que las bozes tengan siempre un mesmo tono».

Capítol XVIII, fol. 39r.

Del modo de herir con dedos convenientes:

«(...) La mano derecha tiene un dedo principal, y la yzquierda dos. El de la mano derecha es el dedo tercero, que es el de en medio, y los dos de la mano yzquierda, son el segundo, y el tercero. Llamanse principales, porque con ellos se comiençan y acaban los redobles y quiebros, con los quales se da gracia a la musica.

Con ningun dedo pulgar se ha de herir en teclas negras, excepto quando se hiere la octava, o quando se offreciere alguna necessidad, que no se pueda hazer otra cosa».

Després de concretar amb diversos exemples les digitacions escaients per a pujar o baixar passos largos de negres o corxeres successives, recomana la utilització dels dits 1, 2, 3 i 4, per a pujar, i afegeix, però, que muchas vezes los dedos se mezclan de otras muchas maneras, amb la qual cosa palesa la seva tolerància tot fugint de dogmatismes.

En el capítol XIX, fol. 45v: Del tañer con buen ayre, formula tres maneres de variar mínimament el ritme del compàs i adverteix: «Téngase aviso, que el detenimiento en las Corcheas no ha de ser mucho».

El capítol XIX, fol. 46v., fa referència a l'ornamentació tot descrivint els redobles i quiebros, dividits en senzillos i reyterados. Aconsella de no fer trinats a les corxeres i semicorxeres, si no és 
imprescindible. També aprofita l'avinentesa per recomanar la forma més escaient de fer els ornaments.

L'obra de Juan Bermudo, Declaración de Instrumentos musicales (1555) ${ }^{5}$, es divideix en cinc llibres independents els uns dels altres. El seu estil és expressiu, però més sever i no tan ordenat com el de Tomás de Santa María. També fa la distinció entre l'orgue i el clavicordi, tot advertint al deixeble que el llibre sol no és suficient, i recomana l'ajut del mestre:

Llibre IV, cap. I.

De algunos avisos para los tañedores:

«(...) No piensen algunos (...) que bastan estos libros para hazer a uno tañedor, sin trabajo. (...) No he visto hombre, que se pueda dezir tañedor: que no ha passado veynte años de continuo estudio. (...) Lo principal que se requiere para ser uno tañedor es la postura de las manos, con que dedos subir, y con quales abaxar para con facilidad hazer los passos dificultosos, con quales dedos redoblar, y en que teclas. Tomad por consejo especial de no aprender esto de barbaros tañedores: porque toda la vida quedareys mancos. Mas vale dar doblados dineros a un buen tañedor porque os enseñe el tiempo necessario: que darlos senzillos, al que no sabe poner las manos en el organo».

Al capítol 43, blasma contra els intèrprets que ornamenten lliurement:

De algunos avisos para los tañedores:

«Exercitandose el tañedor en poner en el monachordio, no haga el oydo a mala Musica porque algo que se hiziere a los principios, querra acabar con ello. Ponga pues obras de excelentes varones. (...) El tañedor sobre todas las cosas tenga un aviso: y es, que al poner la Musica no heche glosas, sino de la manera que esta apuntado: se ha de poner. (...) No se yo como puede escapar un tañedor (poniendo obras de excelentes hombres) de mal criado, ygnorante y atrevido: si las glosa. (...) Y si los ministriles, o cantores della tienen necessidad: piden licencia al que hizo la tal obra, y usan de otros cumplimientos. Y esto no es enmendar sino suplir, o cumplir ruegos de amigos. El tañedor que echa glosas va enmendando, o por mejor dezir borrando, todas la bozes».

Sense voler aprofundir la teoria italiana, és escaient de comentar el tractat de Girolamo Diruta, Il Transilvano ${ }^{6}$. Obra composta en dues parts - impreses el 1593 i el 1609- com un diàleg imaginari, a través del qual l'autor dóna consells i normes. En aquesta Regola per sonar Organi regolatamente con gravità, e leggiadria fa consideracions sobre el comportament del cos i de les mans i numera els dits de l'1 al 5 com prescriu Santa María. Un altre títol, Quali siano le dita buone, e cattive; quali le note buone, e cattive ${ }^{7}$, encapçala la classificació dels dits bons i els dolents. El model de digitacions

5. Bermudo, J., Declaración de Instrumentos musicales. 1555. (Faksimile Nachdruck herausgegeben von Macario Santiago Kastner: Bärenreiter, 1957. Documenta Musicologica, XI).

6. Diruta, G., IL Transilvano. Venezia, Giacomo Vicenti, 1593. Facsímil, Bologna: Forni 1978. 
per a casos concrets el formula de manera diferent que Bermudo i Santa María; Diruta prioritza el tercer dit.

El canvi notable que es produeix el 1600 manifesta un nou art de la composició, que influeix i modifica la interpretació. Les noves obres, amb l'ideal de la paraula i els sentiments, formulen també plantejaments nous que repercuteixen en la tècnica. Com a conseqüència d'aquest fet, hom relega els textos teòrics del segle XVI.

Per altra part, veiem com en l'ornamentació de la música anglesa del període de transició — del 1600 al 1700 — hi excel-leix el llenguatge d'empremta nacional, però sense cap fórmula teòrica com en el cas ibèric o italià. Una influència anglesa força determinant - a la música i a la digitació-, la trobem en Jan Pieterszoon Sweelinck ${ }^{8}$. Les relacions políticoeconòmiques entre Espanya, Anglaterra i els Països Baixos justifiquen les interferències recíproques en el camp musical, de les quals la digitació n'és un testimoni. Per a pujar, l'autor assenyala la mà dreta amb els dits 3, 4, i els 2 i 1 per a l'esquerra; per a baixar, la mà dreta amb els 3,2, i els 2, 3 per a l'esquerra. Permet l'ús del polze i del dit menovell en casos específics, que detalla amb exemples, i també en l'enllaç de figures melòdiques - amb la finalitat de lligar-les-, en les quals utilitza el primer i el cinquè dit. Observem, però, que l'atac que proposa mitjançant la digitació oscil-la simplement entre el legato i el non legato, que, a la pràctica, i segons les formulacions de Sweelinck, és un legato gairebé impossible d'aconseguir.

Els consells que dóna Correa d'Arauxo a la part teòrica del seu llibre Facultad orgánica ${ }^{9}$ són d'una gran importància des del punt de vista teòric i pràctic. Al capítol cinquè especifica el significat de la paraula quiebro i redoble ${ }^{10}$. A la pràctica el quiebro senzillo és un mordent simple i proposa el digitat $3,2,3$ per la mà dreta i 2, 3,2 per la mà esquerra; el quiebro reyterado es produeix com un gruppetto i proposa els dits 4,2, 3 per la mà dreta i 2, 3, 4 per la mà esquerra. Recomana de començar els tientos, motets o versos amb un quiebro o un redoble fet amb el tercer dit quan la mà dreta entra sola, i aconsella que la mà esquerra comenci amb un quiebro amb el segon dit. Mostra un interès especial a ensenyar la manera de distribuir entre les dues mans les veus de les obres en diverses parts, a fi de poder ornamentar amb la mà que resta lliure. ${ }^{11}$ Per a formular una escala ràpida, recomana els dits

7. Idem, op. cit. Part I, f. 6: Quali siano le dita buone, e cattive; quali le note buone, e cattive (...). Sappiate pure, che la cognitione delle ditaè la più importante cosa, che habbi ancor detto, e dichi pur chi vuole, che tal cognitione è di grandissima importanza, et errano quelli, che dicono poco rilevare con qual dito si pigli la nota buona, e cattiva. El model d'una escala serveix d'exemple per a la classificació de les notes: (...) Il primo ditto fa la nota cattiva, il secondo la buona, il terzo la cattiva, il quarto la buona, il quinto la cattiva: e il secondo, terzo e quarto dito sonno quelli, che fanno totta la fatica... El plantejament sobre la classificació dels salts bons i dolents rep la resposta següent: (...) Il salto buono, è, quando le note saltano, ò do ottava, ò di sesta, ò d'altri intervalli consonanti, e dissonanti; pur che sia la nota buona, quella que salta (...). Il salto cattivo è, quando salta la nota cattiva... El significat de nota buona i nota cattiva, Diruta no l'arriba a precisar; hom el podria traduir per nota pesant i nota lleugera.

8. SweElinck, J.P., Opera Omnia. I: The Instrumental Works / Edited by Gustav Leonhardt, Alfons Annergan, Frits Noske. Amsterdam: [Printed by Nirota], 1968.

9. Correa D'Arauxo, F., Libro de tientos y discursos de musica practica y theoria del organo. Intitulado Facultad Organica. Alcalá de Henares, 1626. Edició facsímil. Genève: Minkoff, 1981 / Altra edició: Transcripción y estudio de Macario Santiago Kastner. Madrid: Unión Musical Española, 1980.

10. Idem, op. cit., fol. 15v. «Quiebro es: (inclinatio, \& erectio, duobus, I. tribus signis continuis, facta velociter) una baxada y subida hecha con velocidad en dos o tres signos. Redoble es: (reduplicatio, I. repercussio duorum signorum propinquorum, cum inclinatione, \& erectione in fine facta velociter) es una repercusion de dos signos propinquos con quiebro senzillo)». 
2, 3, 4 o 1, 2, 3, 4 de la mà dreta per a pujar i baixar, i els 3,2, 1 o 4,3,2, 1 de la mà esquerra per a pujar i baixar, a més d'altres digitats mixtes. Les lliçons de Correa són més sintètiques que les de Santa María, més precises i clares. Cal valorar sobretot les digitacions mixtes que permeten una gran varietat d'articulacions. Tractats com el de Lorenzo Penna $(1684)^{12}$-model que seguí José de Torres $^{13}$ - , dividit en tres llibres ${ }^{14}$, dediquen bona part del seu contingut a qüestions de teoria, a les regles del contrapunt $\mathrm{i}$ als problemes que planteja el baix continu, amb títols com Fondamenti per a suonare l'organo ò clavicembalo. ${ }^{15}$ També cal citar Alessandro Poglietti (1676), el qual en la seva obra dóna consells molt interessants, tot fent referència a la digitació i l'ornamentació. ${ }^{16}$

Hem de remarcar els prefacis d'alguns volums en els quals -encara que no siguin dedicats pròpiament a la teoria- els compositors donen instruccions sobre la interpretació; així ho fan el carmelità Spiridion al seu tractat Nova Instructio, imprès el 1669, i Giovanni Maria Trabaci, que, al pròleg de Ricercate, Canzone francese (1603), estableix normes sobre la pràctica de l'ornamentació, el tempo, etc. Frescobaldi, l'obra per a teclat del qual porta el títol genèric de Toccate et Partite d'Intavolatura di Cimbalo et Organo, aporta uns valuosos consells al pròleg del primer llibre, tot recomanant la llibertat en la interpretació. ${ }^{17}$

Amb una precisió clara, altres autors francesos com Chambonnières, d'Anglebert, Couperin i Saint Lambert, ${ }^{18}$ determinen en el títol l'instrument per al qual componen. Diversos compositors proposen un codi personal d'ornaments que, al llarg del temps, avança cap a la virtuositat. Aquests es converteixen en accents o en elements formals de la melodia, i la llibertat d'escollir-los i d'interpretarlos comporta errors i excessos. La repetició, en les danses de la música francesa del segle XVII — la majoria en dues parts-, és un element que, juntament amb l'ornamentació, genera el principi de la

11. Idem, op. cit., fol. 16v. «Si entran tres vozes a la par, lo mas hordinario es: dar las dos mas baxas con la izquierda, y la mas alta con la derecha: porque quede libre para adornar la obra con quiebro, o redoble».

12. Penna, L., Li Primi Albori Musicali. Bologna: Giacomo Monti, 1684.

13. Torres Martínez Bravo, J. de, Reglas generales de acompañar en Organo, Clavicordio y Harpa. Madrid, 1702. Edición facsímil. Madrid: Arte Tripharia, 1983.

14. Idem. op. cit. Distinti in tre libri; Principi del CANTO FIGURATO. Regole del CONTRAPUNTO. Fondamenti per suonare l'ORGANO Ò CLAVICEMBALO sopra la parte.

15. Idem. op. cit. Al llibre II, capítol XVIII: Del Basso continuo. Regles i exemples per a la realització del baix continu. El capítol XXIV, Alcuni avertimenti de farsi e altri da fugirsi nel Suonare l'Organo sù la Parte; conté vint regles, algunes dedicades a la digitació, l'articulació i la realització del baix continu; en presentem una mostra: 2. Ascendendo la Mano destra, le dita se movino uno dopo l'altro, e prima il medio, doppo l'annulare, e poi il medio, e cosí à vocenda si caminijno, mentre però non suonassero le dita insieme; mà nel discendere si mutino il medio, poi l'Indice poscia il medio etc. e nel discendere, il medio, poi l'annulare, etc. Com podem observar, reduir la digitació al comportament del tercer dit és simplificar molt la seva finalitat. 7. Stà molto bene il suonar ligato, ogni volta, che non si molesti la parte Cantante. 19. Procuri arppegiare per non lasciar vuoto l'instrumento. El darrer consell és similar al que dóna Frescobaldi al pròleg de les seves Toccate.

16. Poglietti, A., Compendium oder Kurtzer Begriff und Einführung zur Musica, 1676.

17. Frescobaldi, G., Toccate et Partite d'Intavolatura di Cimbalo et Organo. Roma 1637. Edició facsímil. Firenze: Edizione Scelte, 1980. (Archivum Musicum). Hi llegim: Al Lettore: Primieramente: che non dee questo modo di sonare stare soggetto a batutta. Amb una referència expressa als affetti, secondo i loro affetti, aconsella arpegiar lentament el començament de les toccate: Li cominciamenti delle toccate sieno fatte adagio, et arpeggiando. Le cadenze benché sieno scritte veloce conviene sostenerle assai. Podem comprovar com l'affetto es converteix en l'element central d'aquesta música; interpretar-lo és endinsar-se en l'essència de l'obra. Nelle Partite quando si troveranno passagi, et affetti sarà bene di pigliare il tempo largo; il che osservassi anche nelle toccate.

18. SAINT-LAmBERT, M., Les principes du clavecin, contenant une explication exacte de tout ce qui concerne la Tablature \& le Clavier. Paris 1702. Edició facsímil. Genève: Minkoff, 1974. Saint Lambert, com altres mestres de clavicèmbal, recomana fer els trinats amb els dits $3 / 2$ o $4 / 3$ per a la mà dreta, i els $1 / 2$ o $2 / 3$ per a la mà esquerra, però insisteix també a fer sevir tots els dits. 
variació. Al segle XvIII, la funció dels instruments és complexa. Com ja s'ha comentat, l'escissió orgue/clavicèmbal, tant pel que fa a la composició com a la tècnica, s'esdevé al segle XvII. Diruta comenta la prohibició feta pel Concili de Trento de tocar danses a l'església: Perche causa li Sonatori da Balli non riescono nel sonar Organi. ${ }^{19}$ A continuació posa de relleu la diferència de l'orgue amb altres instruments de teclat: Modo di sonar musicalmente nell'istromenti da penna. ${ }^{20}$ L'orgue rep el qualificatiu d'instrument seriós, espiritual, i hom adjudica al clavicèmbal la funció més mundana de la música de dansa. Una altra font interessant és el digitat de la primera toccata del Primo e Secondo Libro di Toccate d'Alessandro Scarlatti. ${ }^{21}$

També cal citar les Sonate per Cembalo de Bernardino della Ciaja, ${ }^{22}$ en les quals inclou com a curiositat històrica un glissando amb altres indicacions expressives com Stentato, Languente i botta forte.

Al igual que J. S. Bach, la personalitat de François Couperin representa, a França, el punt àlgid de la literatura per a clavicèmbal. La seva obra pedagògica, L'art de toucher le clavecin, del 1717, ${ }^{23}$ constitueix la primera escola de clavicèmbal —en un sentit modern del terme-, que d'una manera clara intenta trencar la distància existent entre les notes i la bona interpretació; la seva obra pedagògica mostra la posició correcta del cos i de les mans, tot rebutjant les manifestacions externes del peu o del cap i afegint consells de bon músic i d'excel-lent pedagog. El problema de la digitació el resol amb curts exemples aplicats a les seves obres. ${ }^{24}$ Alguns elements, que amb nom de suspension, cessation i aspiration conté la seva taula d'ornaments, no són especialment comentats per l'autor; es podrien classificar com a maneres diferents d'atacar les notes, tot definint-los com una faisó expressiva del discurs musical. Cal precisar el valor que Couperin dóna al joc legato, que hom pot comprovar a les seves digitacions, el coneixement de les quals permet d'articular i frasejar d'una manera fidel segons el gust del seu temps. En aquesta línia, hem de recordar J. Ph. Rameau, compositor i teòric que escriu, al suplement del segon llibre, Pièces de clavecin, un Méthode pour la méchanique des doigts, où l'on enseigne les moyens de se procurer une parfaite exécution sur cet instrument, et avec une table pour les agréments. ${ }^{25}$ Aquest compendi presenta la novetat d'una digitació que va en la direcció moderna. El desenrotllament del polze rep una aplicació anatòmica, i destina els dits 2, 3, 4, a les tecles alterades.

El teòric alemany Friedrich Wilhelm Marpurg rep la influència francesa a París quan es posa en contacte —entre el 1746 i el 1749 — amb personalitats com Voltaire, Mapertuis, d'Alembert i

19. Op. cit., fol. 5v. Che nelli Organi di Chiesa non si debanno sonare Passi e Mezzi, e altre sonate da ballo, nè meno Canzone lascive e dishoneste.

20. Op. cit., fol. 5v. Molti Organisti non li riesce il lor sonare musicale nelli istromenti da penna (...) Quando sonarete nell'Istrumento da penna tal note li mancherà più della metà della armonia. Bissogna dunque con la vivacità e destrezza della mano supplire tal mancamento con percuotere, piu volte il Tasto.

21. Scarlatti, A., Primo e Secondo Libro di Toccate. Napoli, [s. d.]. Edició facsímil. Firenze: Edizione Scelte, 1981.

22. Della Ciaja, B., Sonate per Cembalo. Roma 1727. Edició facsímil. Firenze: Edizione Scelte, 1979.

23. Couperin, F., L'art de toucher le clavecin. Paris: Chés l'Auteur, 1717.

24. Idem. La façon de doigter sert beaucoup pour bien jouer; mais, comme il faudroit un volume entier de remarques, et de passages variés pour démontrer ce que je pense; et ce que je fais practiquer à mes elèves, je n'en donneray icy qu'une notion générale.

25. Rameau, J.Ph., Pièces de Clavecin avec une méthode pour la mécanique des doigts, où l'on enseigne les moyens de se procurer une parfaite exécution sur cet instrument, et avec une table pour les agréments. (1724, reeditat el 1731). 
Rameau. L'ideal que cercava aquest autor no era el d'ensenyar a compondre sinó el d'aconseguir un bon ensenyament de la música en general: teoria, estètica, crítica musical i, fins i tot, publicacions musicals. Hi és ben palesa la influència del racionalisme francès. Die Kunst das Clavier zu spielen és del 1750, i el 1756, apareix la seva traducció francesa; també el 1756, a Berlín, surt a la llum Principes $d u$ Clavecin. ${ }^{26} \mathrm{El}$ primer capítol porta aquest títol: Du maître, de l'instrument du Tempérament du Clavecin, de la possition du corps, et de la main; el capítol XXII ens parla De la position des doigts. L'escola de teclat de Marpourg va aconseguir molt d'èxit, fruit sistemàtic de les escoles de Couperin i de Rameau.

La situació canvia a l'entorn del 1750 amb el desenvolupament i l'acceptació general del fortepiano. La qüestió que es planteja en el seu moment rau en la influència del clavicordi sobre el fortepiano i la seva expansió. Al segle XVIII, el clavicordi fou un instrument construit d'una manera senzilla, la qual cosa el feia assequible a tothom; la seva utilitat no era altra que la de practicar a casa $\mathrm{i}$ servir d'ajut en la composició. La gran possibilitat de matisos i la varietat en el color del so influiren en el fet que, vers la meitat del segle, es convertís en l'instrument de moda. Cap el 1700, l'invent de la mecànica de martells — sense una connexió rígida amb les tecles-, havia contribuit al seu desenvolupament; els primers passos els fa Cristofori ${ }^{27}$ a Itàlia i, paral-lelament, Christoph Gottlieb Schröter ho implanta a Alemanya. Al començament del 1730, el constructor alemany Gottfried Silbermann sol-licita en dues ocasions i sense cap èxit -1730 i 1740-, l'opinió personal de J. S. Bach. Finalment, el 1747, aconsegueix de ser rebut en audiència a Postdam per Frederic el Gran. La tasca de Silbermann va influir en les millores tècniques i sonores de l'instrument.

El 1753 apareixen a Berlín dos influents tractats compostos per Johann Joachim Quantz i Carl Philipp Emanuel Bach. El títol de l'obra del d'aquest darrer, Versuch über die wahre Art das Clavier $z$ u spielen, publicada el 1753 i novament el 1762, no indica plenament el seu contingut. Bach s'inspira en els mètodes francesos titulats Essai sur..., tot canviant la paraula clavecin per clavier. Marpurg parlava del clavicèmbal; Bach, del clavicordi. Johann Sebastian Bach, al Klavierbüchlein für Anna Magdalena Bach, del 1725, dóna algunes regles elementals sobre el baix continu, però la seva negativa a escriure qualsevol mètode podem afirmar que es fonamenta en la força de la pràctica verbal, és a dir, en l'autoritat que atorga el control del mestre. Aquest també podria ser el motiu dels pocs exemples pràctics de digitació que Bach va deixar. (Preambulum en sol m, del Klavierbüchlein für Wilhelm Friedmann i Applicatio, BWV 994, que conté elements de digitació antiga). És coneguda la frase que

26. Marpourg, F.W., Principes du Clavecin. Berlin: Chez Haude et Spener, 1756. Edició facsímil. Genève: Minkoff, 1974. Remarquem algunes frases de la introducció. «Per tal que el digitat sigui correcte cal tenir en compte dues coses: la comoditat i la «gràcia»... Si la posició de la mà no és còmode hi ha el perill d'equivocar les notes... La «mauvaise grace» forma part d'una posició incòmode... El digitat no és una cosa tan arbitrària com imaginen alguns cembalistes... I: Cada dit llarg, pot passar per damunt d'un de curt; II: No s'ha de fer servir el mateix dit dues vegades seguides, ni sobre la mateixa tecla ni sobre dos graus diferents (excepte en casos especials); III: Cal canviar un o més dits per tal de facilitar les notes seguides: IV: Per tal de lligar la nota precedent i la que segueix és necessari substituir el dit sobre la mateixa nota; V: Quan una mà té un excés de notes i no les pot tocar totes, necessita l'ajut de l'altra; VI: Quan les parts s'entrecreuen, cal passar una mà per damunt de l'altra; VII: Quan les dues parts d'una peça es troben sobre la mateixa nota, és necessari tocar-la amb les dues mans; VIII: Tots els trinats i els mordents de la mà dreta es fan amb el 2,3 o 3,4. Els de l'esquerra amb el 1,2 o el 2,3, perquè són els dits més àgils. En un cas extraordinari es pot trinar amb el 3,5 o el 2,4; i X: Fa referència a la digitació dels acords de dues, tres i quatre notes.

27. Restle, K., Bartolomeo Cristofori und die anfänge des Hammerklaviers. München: Maris, 1991. 
C. Ph. E. Bach escriu a l'autobiografia, en la qual afirma: «En la composició i en la manera de tocar l'instrument, no vaig tenir cap altre mestre que el meu pare». Considerat com una autoritat en el camp de la pedagogia, podem establir la hipòtesi que C. Ph. E. Bach en el Versuch... ordena i sistematitza les ensenyances rebudes del seu pare. Una anàlisi de l'estat de la qüestió a l'època de J. S. Bach, ens la presenta Günther Wagner: ${ }^{28}$

1. Des dels anys joves de J. S. Bach, intèrprets molt coneguts usaven el polze d'una manera restringida.

2. Bach visqué el «canvi especial» del gust musical.

3. Aquest canvi estilístic formulava la necessitat d'una nova digitació.

4. Bach va aportar, ell mateix, un canvi a la digitació.

5. La nova digitació considerava el polze no com un dit utilitari, sinó com un dit principal.

6. El polze va ser utilitzat segons la seva forma natural i la seva constitució.

7. La nova digitació cobria totes les tonalitats, fins i tot els tons amb moltes alteracions.

Si observem la primera part del Versuch... de C. Ph. E. Bach, podem comprovar com el clavicèmbal fa la funció d'instrument de grans conjunts mentre que el clavicordi és destinat a tocar com a solista i el fortepiano mereix la consideració de novetat. La part més important del llibre està dedicada a la digitació i als seus procediments. ${ }^{29} \mathrm{El}$ darrer capítol del primer llibre parla de l'acompanyament, i serà ampliat, nou anys més tard, a la segona part en tractar del baix continu. El comportament i la lliure utilització del polze té una consideració similar a la dels altres dits. La seva funció és la d'alleugerir i possibilitar la distensió de la mà en relació amb els dits. Hi podem observar l'avenç en la digitació respecte a l'antiga, però trobem una certa analogia evolucionada amb la descripció de la tècnica que en fa Santa María. C. Ph. E. Bach al Versuch über die wahre Art das Klavier zu spielen palesa, com cap altre pedagog del seu temps, no solament la part tècnica de la música, sinó també el sentit intern i expressiu de la interpretació musical, tot emprant les possibilitats descriptives del llenguatge.

L'obra de Daniel Gottlob Türk, Klavierschule, oder Anweisung zum Klavierspielen für Lehrer und Lernende (1789), ${ }^{30}$ és la darrera obra pedagògica del segle XVIII que abraça tota mena d'instruments de teclat, 18 en total, alguns d'ells força rars. Sobre el clavicèmbal, el clavicordi i el fortepiano Türk repeteix el que van dir els seus predecessors, Couperin, Rameau, Carl Philipp Emanuel Bach o Löhlein. Ordena la seva obra pedagògica — pensada bàsicament per al clavicordi — plantejant, en primer lloc, qüestions tècniques i d'expressió musical. Pel que fa a la digitació, la considera una part

28. Wagner, G., Das Spiel auf dem Kielflügel: Ein historischer Überblick a Kielklaviere, Staatliches Institut für Musikforschung Preussischer Besitz, Berlin, 1981, p. 361.

29. ВАCH, C.Ph.E., Versuch über die wahre Art das Klavier zu spielen. Kritish redivierter Neudruck nach unveränderten jedoch verbesserten zweiten Aufläge des Originals. Berlin 1753 und 1762. Mit einem Vorwort und erläutenden Anmerkungen versehen von Dr. Walter Niemann. [s. 1.]: Kahnt 1972. Al capítol inicial dóna les nocions preliminars: «El mètode just per a fer sonar els instruments de teclat es basa essencialment en tres components: digitació adequada, ornaments correctes, la bona interpretació». 30. TüRK, J.D., Klavierschule. Leipzig: Schwickert, 1789. 
essencial i en molts aspectes determinant. Accepta tot el que estalvia moviments i es lamenta que, malgrat la difusió de tractats, l'ús del polze no sigui una norma universalment establerta. Confirma, una vegada més, la interrelació entre la digitació i el fraseig i resumeix la seva matèria en deu regles fonamentals que coincideixen amb l'esperit de Marpurg i, bàsicament, amb el de C. Ph. E. Bach. El discurs, però, d'aquest darrer autor és dedicat als amateurs i als dilettanti; el de Türk, en canvi, és dirigeix als virtuosos, el repertori dels quals precisa una formació tècnica adequada. Hem de recordar que quan aparegué la primera edició de la Klavierschule el 1789, C. Ph. E. Bach ja feia un any que havia mort. Finalment també caldria esmentar l'obra dedicada al clavicèmbal de Nicolò Pasquali, publicada el $1798^{31}$ en la qual podem observar el desenvolupament de la digitació a la darreria del segle; també és escaient de ressaltar una altra obra del mateix autor sobre el baix continu pels ornaments digitats que presenta. ${ }^{32}$

La finalitat d'aquest comentari sobre l'evolució del digitat als instruments de teclat posa de relleu la rellevància dels teòrics ibèrics — capdavanters, entre d'altres matèries — en tot allò que fa referència al digitat dels instruments de teclat.

31. Pasquali, N., The Art of Fingering the Harpsichord. Edinburgh, 1798.

32. Pasquali, N., Through-Bass Made Eassy. London, 1763 Facsimile. Oxford: Oxford University Press, 1974. 